\title{
Clinical Profile of Migraine Headache with Special Reference to Trigger Factors in Medical College Set Up
}

\author{
Dr Anantha Guruswamy ${ }^{1}$, Dr Sreekantaswamy ${ }^{2}$, Dr Kavitha BB ${ }^{3}$ \\ ${ }^{1}$ Postgraduate Student in Department of Neurology, Vydehi Institute of Medical Sciences and Research Centre, Bangalore, Karnataka, India \\ ${ }^{2}$ Professor in Department of Neurology, Vydehi Institute of Medical Sciences and Research Centre, Bangalore, Karnataka, India
}

${ }^{3}$ Postgraduate Student in Department of Pharmacology, Vydehi Institute of Medical Sciences and Research Centre, Bangalore, Karnataka, India

\begin{abstract}
Background and objectives: Migraine is one of the disabling primary headache in the population. It affects the individual and society at large by loss of productivity by the sufferers and enormous economic burden. There are multiple factors which can trigger migraine. If properly controlled, it can reduce the burden of migraine. Health care professionals are exposed to multiple trigger factors like sleep disturbance, stress and untimely food habits which give rise to increase in migraine frequency. We conducted this study of detailed clinical profile and trigger factors among the 2050 subjects (MBBS students: 909, BDS students: 323, Nursing students: 268, Post graduates students and staff: 550) in our medical institute Methods: Subjects were given questionnaires on migraine headache and instructed to give details of clinical features with special reference to trigger factors. The assessment tools used were visual analogue scale (VAS) and migraine disability assessment scale (MIDAS). Results: Out of 2050 subjects 697 suffered from migraine headache. The overall prevalence of migraine headache was $34 \%$. Out of which females had higher prevalence (66.1\%) as compared to males (33.8\%). Headache experienced by majority of student population was unilateral (31.4\%), pulsating type (51.6\%) and of moderate intensity (77.1\%). Common associated symptoms were nausea associated with other factors (40\%) and photophobia \& phonophobia (18.6\%). Stress (72.1\%) \& decreased sleep (49.4\%) were the most common triggering factors. Practice of self-medication was reported by $80.2 \%$ of subjects. Specific anti migraine medication use in migraineurs was found to be low (7.7\%) showing inadequate management of migraine headache in our study population. Conclusion: Our study noted high frequency of trigger factors in medical professionals and most common triggering factor was stress and disturbed sleep. There was very low usage of specific anti migraine medications among them. To our knowledge this is the first large study to evaluate migraine among medical professionals.
\end{abstract}

Keywords: Headache, Migraine, Trigger factors.

\section{Introduction}

Headache is a common neurological disorder, which is associated with significant disease burden. Headache affects work, social and leisure activities and has a tremendous impact on a person's life ${ }^{[1],[2]}$. Headache research has focused on both general populations and specific groups such as adolescents, college undergraduates, people in the workplace and persons with potentially related co morbidities such as epilepsy and psychiatric illnesses ${ }^{[3]}$.Globally, it has been estimated that prevalence among adults of current headache disorder (symptomatic at least once within the last year) is $47 \% .11 \%$ have migraine, $42 \%$ have tension-type headache (TTH), and 3\% have chronic daily headache ${ }^{[4]}$. Half to three quarters of the adults aged 18-65 years in the world have had headache in the last year and among those individuals, more than $10 \%$ have reported migraine. Headache on 15 or more days every month affects $1.7-4 \%$ of the world's adult population. Despite regional variations, headache disorders are a worldwide problem, affecting people of all ages, races, income levels and geographical areas. In the Global Burden of Disease Study, updated in 2004, migraine on its own was found to account for $1.3 \%$ of years lost due to disability. Headache disorders impose a recognizable burden on sufferers including sometimes substantial personal suffering, impaired quality of life and financial cost. Repeated headache attacks, and often the constant fear of the next one, damage family life, social life and employment. The long-term effort of coping with a chronic headache disorder may also predispose the individual to other illnesses. For example, depression is three times more common in people with migraine or severe headaches than in healthy individuals. Economic burden of headache disorders are a public-health concern given the large amount of associated disability and financial costs to society. As headache disorders are most troublesome in the productive years (late teens to 50s), estimates of their financial cost to society - principally from lost working hours and reduced productivity - are massive. In the United Kingdom, for example, some 25 million working- or schooldays are lost every year because of migraine alone; this financial cost is matched by TTH and chronic daily headache combined ${ }^{[5]}$.

Migraine is a chronic neurovascular disease. It is characterized by a state of neuronal hyperexcitability, with abnormal modulation involving several receptors and ion channels at several sites including the cerebral cortex, the trigemino vascular system, and brainstem nuclei ${ }^{[6]}$ Migraine is divided into two major subtypes, migraine with aura and migraine without aura. Migraine without aura is most common type ${ }^{[7]}$. The International Headache Society (IHS) defines migraine without aura as a recurrent headache disorder with attacks lasting from 4 to 72 hours and is unilateral, pulsatile, and of moderate to severe intensity, and symptoms are associated with nausea, vomiting, 


\section{International Journal of Science and Research (IJSR) \\ ISSN (Online): 2319-7064 \\ Index Copernicus Value (2015): 78.96 | Impact Factor (2015): 6.391}

photophobia or phonophobia ${ }^{[8]}$.The prevalence of migraine is $10 \%$ worldwide. The World Health Organization ranks migraine 19th on the list of diseases worldwide that cause disability ${ }^{[9]}$. Migraine is due to neuronal hyper excitability of ophthalmic branch of the trigeminal nerve which innervates cerebral blood vessels, dural vessels and other intracranial structures. It causes spontaneous depolarization which results in release of neuropeptides like substance $P$, neurokinin A, calcitonin gene related peptide etc. It leads to neuronal inflammation of trigeminal nerve which causes vasodilatation of cranial blood vessels, leakage of plasma proteins from dural vessels, mast cell degranulation, and activation of cellular immune response. According to Reuter et al., migraine with aura is due to cortical spreading depression which stimulates trigeminal nerve spontaneously and results in neurogenic inflammation ${ }^{[10]}$.Trigger factors of migraines, are defined as factors that, in isolation or in combination with other factors, induce a crisis in susceptible individuals ${ }^{[11]}$ and generally precede a crisis by less than 48 hours ${ }^{[12]}$. Many of these factors have been reported, such as those related to food, hormones, and the environment, with stress being one of the most common ${ }^{[13][14]}$. Despite this, there is little evidence to conclusively correlate the majority of these factors with the initiation of a crisis ${ }^{[15]}$.

\section{Materials and Methods}

This is cross sectional, prospective type of study, which included 2050 subjects. This is conducted in Vydehi Institute of Medical Sciences and Research Centre (VIMS \& RC), Bengaluru. Duration of this study was from June 2013 to Dec 2015. Medical students, Dental students, Nursing students, Post graduates and teaching / non-teaching staff of VIMS \& RC who have headache have been recruited Approval for the study protocol was obtained from the institutional health research and ethics committee.International headache society criteria.Visual Analogue Scale (VAS) and Migraine Disability Assessment (MIDAS) were used as assessment tools. Subjects in the age range of 18-70 years of either gender and who is suffering from headache were included. Subjects diagnosed of secondary headaches and who were unwilling to give consent were excluded. Analysis was undertaken using SAS system (version 9.2).

\section{Results}

\subsection{Demographic and Clinical Characteristics}

The sample consisted 2050 participants of both gender. The studied population were from a medical college setup consisting of MBBS, BDS, Nursing, Post Graduates and Staff.

\subsection{Socio-demographic characteristics}

Table 1.1: Age

\begin{tabular}{|c|c|c|c|c|}
\hline Age & $\mathrm{N}$ & Migraine & No Headache & TTH \\
\hline $18-25$ & $1554(75.8 \%)$ & $552(26.9 \%)$ & $656(32 \%)$ & $346(16.8 \%)$ \\
\hline $26-35$ & $344(16.7 \%)$ & $96(4.6 \%)$ & $167(8.1 \%)$ & $81(3.9 \%)$ \\
\hline $36-45$ & $132(6.4 \%)$ & $44(2.1 \%)$ & $54(2.6 \%)$ & $34(1.6 \%)$ \\
\hline$>45$ & $20(0.9 \%)$ & $5(0.2 \%)$ & $12(0.5 \%)$ & $3(0.1 \%)$ \\
\hline
\end{tabular}

The mean age of the samples was 23.56 years $( \pm 6.0)$

Table 1.2: Gender

\begin{tabular}{|c|c|c|c|c|}
\hline Gender & $\mathrm{N}$ & Migraine & No Headache & TTH \\
\hline Female & $1274(62.1 \%)$ & $461(66.1 \%)$ & $544(61.1 \%)$ & $269(57.9 \%)$ \\
\hline Male & $776(37.8 \%)$ & $236(33.8 \%)$ & $345(38.8 \%)$ & $195(42.0 \%)$ \\
\hline
\end{tabular}

The study group had 1274 females and 776 males of whom 461females and 236 males had migraine headache.

Table 1.3: Course

\begin{tabular}{|c|c|c|c|c|}
\hline Course & $\mathrm{N}$ & Migraine & No Headache & TTH \\
\hline MBBS & $909(44.3 \%)$ & $357(51.2 \%)$ & $364(41 \%)$ & $188(40.5 \%)$ \\
\hline BDS & $323(15.7 \%)$ & $108(15.4 \%)$ & $117(13.1 \%)$ & $98(21.1 \%)$ \\
\hline Nursing & $268(13.0 \%)$ & $74(10.6 \%)$ & $148(16.6 \%)$ & $46(9.9 \%)$ \\
\hline PG's and Staff & $550(26.8 \%)$ & $158(22.6 \%)$ & $260(29.2 \%)$ & $132(28.4 \%)$ \\
\hline
\end{tabular}

The study group consisted of 2050 participants, $44.3 \%$ were MBBS students $15.7 \%$ were BDS students, $13 \%$ were nursing students and $26.8 \%$ belonged to post graduates and staff.

Table 2: Clinical data of migraine characteristics:

Table 2.1: Premonitory symptoms

\begin{tabular}{|c|c|}
\hline Migraine & Frequency and Percentage \\
\hline Migraine with aura & $156(22.3 \%)$ \\
\hline Migraine without aura & $541(77.6 \%)$ \\
\hline
\end{tabular}

In our study out of 2050 participants 697 had migraine type of headache, $22.3 \%$ had migraine with aura and $77.6 \%$ had migraine without aura.

Table 2.2: Duration of Headache

\begin{tabular}{|c|c|}
\hline Duration of Headache & Frequency and Percentage \\
\hline$<1$ month & $55(7.8 \%)$ \\
\hline 1-3months & $226(32.4 \%)$ \\
\hline 3-6months & $173(24.8 \%)$ \\
\hline 6-12 months & $65(9.3 \%)$ \\
\hline$>12$ months & $178(25.5 \%)$ \\
\hline
\end{tabular}

In the study group $32.4 \%$ of them had headache of $1-3$ months duration followed by $>12$ months in $25.5 \%, 3-6$ months among $24.8 \%, 9.3 \%$ reported of 6-12 months duration and $7.8 \%$ reported $<1$ month duration of headache.

Table 2.3: Duration of Attack

\begin{tabular}{|c|c|}
\hline Duration of each attack & Frequency and Percentage \\
\hline $4-12$ hours & $603(86.5 \%)$ \\
\hline $12-24$ hours & $71(10.1 \%)$ \\
\hline $24-48$ hours & $13(1.8 \%)$ \\
\hline $48-72$ hours & $10(1.4 \%)$ \\
\hline
\end{tabular}

$86 \%$ of them reported 4-12 hours duration of each attack, while $10.1 \%$ reported $12-24$ hours, $1.8 \%$ reported $24-48$ hours and $1.4 \%$ reported $48-72$ hours. 


\section{International Journal of Science and Research (IJSR) \\ ISSN (Online): 2319-7064 \\ Index Copernicus Value (2015): 78.96 | Impact Factor (2015): 6.391}

Table 2.4: Number of attacks in a month

\begin{tabular}{|c|c|}
\hline Number of attacks in a month & Frequency and Percentage \\
\hline $5-10$ & $618(88.6 \%)$ \\
\hline $10-15$ & $58(8.3 \%)$ \\
\hline$>15$ & $21(3.0 \%)$ \\
\hline
\end{tabular}

In our study $88.6 \%$ reported 5-10 attacks in a month , 8.3\% of them reported 10-15 attacks and $3 \%$ of them reported $>15$ attacks per month.

Table 2.5: Onset of each attack

\begin{tabular}{|c|c|}
\hline Onset of each attack & Frequency and Percentage \\
\hline Gradual & $453(64.9 \%)$ \\
\hline Sudden & $244(35.0 \%)$ \\
\hline
\end{tabular}

$64.9 \%$ of them reported gradual onset of each attack while $35 \%$ of them reported sudden onset of each attack.

Table 2.6: Time of Occurrence

\begin{tabular}{|c|c|}
\hline Time of Occurrence & Frequency and Percentage \\
\hline Morning & $140(20.0 \%)$ \\
\hline Afternoon & $225(32.2 \%)$ \\
\hline Evening & $187(26.8 \%)$ \\
\hline Nocturnal & $22(3.1 \%)$ \\
\hline Mixed/Varied & $123(17.6 \%)$ \\
\hline
\end{tabular}

$32.2 \%$ of them reported attack of migraine occurred mostly during afternoons while $26.8 \%$ reported evening, $20 \%$ reported morning, $17.6 \%$ reported mixed/varied and only $3.1 \%$ of them reported nocturnal.

Table 2.7: Site

\begin{tabular}{|c|c|}
\hline Site & Frequency and Percentage \\
\hline Unilateral & $219(31.4 \%)$ \\
\hline Bifrontal & $96(13.7 \%)$ \\
\hline Temporal/Temple & $121(17.3 \%)$ \\
\hline Occipital & $21(3.0 \%)$ \\
\hline More than one type & $154(22.0 \%)$ \\
\hline Orbital & $3(0.4 \%)$ \\
\hline Holocranial & $50(7.1 \%)$ \\
\hline Changing & $33(4.7 \%)$ \\
\hline
\end{tabular}

In our study $31.4 \%$ of them reported unilateral headache and $22 \%$ of them reported more than one type of headache while $17.3 \%$ of them reported of temporal, $13.7 \%$ of them reported bifrontal, $7.1 \%$ reported holocranial, $4.7 \%$ reported changing type, $3 \%$ reported occipital and $0.4 \%$ of them reported orbital.

Table 2.8: Nature of pain

\begin{tabular}{|c|c|}
\hline Quality/Nature of Pain & Frequency and Percentage \\
\hline Pulsating & $360(51.6 \%)$ \\
\hline Throbbing & $129(18.5 \%)$ \\
\hline Bursting & $24(3.4 \%)$ \\
\hline Band like & $21(3.0 \%)$ \\
\hline Shooting & $10(1.4 \%)$ \\
\hline More than one type & $153(21.9 \%)$ \\
\hline
\end{tabular}

The most characteristic headache was pulsating which was seen in $51.6 \%$ of the participants followed by more than one type in $21.9 \%$, throbbing in $18.5 \%$, bursting type was reported in $3.4 \%, 3 \%$ reported band like and $1.4 \%$ reported shooting type.

Table 2.9: Intensity of pain

\begin{tabular}{|c|c|}
\hline Visual Analogue Scale for Pain & Frequency and Percentage \\
\hline Mild(0-4) & $95(13.6 \%)$ \\
\hline Moderate(5-7) & $538(77.1 \%)$ \\
\hline Sever(8-10) & $64(9.1 \%)$ \\
\hline
\end{tabular}

$77.1 \%$ of them reported of moderate intensity of pain on visual analogue scale, $13.6 \%$ of them reported mild and $9.1 \%$ of them reported of sever intensity.

Table 2.10: Family history

\begin{tabular}{|l|l|}
\hline Family history & Frequency and Percentage \\
\hline Present & $166(23.8 \%)$ \\
\hline Absent & $531(76.1 \%)$ \\
\hline
\end{tabular}

In our sample $76.1 \%$ of them reported of having no family history of migraine while $23.8 \%$ of them had family history of migraine.

Table 2.11: Relieving factors

\begin{tabular}{|l|l|}
\hline Relieving factors & Frequency and Percentage \\
\hline Rest & $407(58.3 \%)$ \\
\hline Sleep & $496(71.1 \%)$ \\
\hline Massage & $188(26.9 \%)$ \\
\hline Vomiting & $44(6.3 \%)$ \\
\hline Entertainment & $66(9.4 \%)$ \\
\hline Change of Posture & $18(2.5 \%)$ \\
\hline
\end{tabular}

$71.1 \%$ of them reported sleep as relieving factor while $58.3 \%$ of them reported of rest as relieving factor, $26.9 \%$ reported massage, $9.4 \%$ of them reported entertainment, $6.3 \%$ reported vomiting and $2.5 \%$ of them reported of change of posture as relieving factor.

Table 2.12: Medications

\begin{tabular}{|c|c|}
\hline Medications & Frequency and Percentage \\
\hline NSAID'S & $471(67.5 \%)$ \\
\hline Opioids & $17(2.4 \%)$ \\
\hline Prophylactic & $54(7.7 \%)$ \\
\hline Triptans & $14(2.0 \%)$ \\
\hline Homeopathy & $3(0.4 \%)$ \\
\hline
\end{tabular}

In our study $67.5 \%$ of them used NSAID's, $2,4 \%$ used opioids , $2 \%$ used triptans, $0.4 \%$ used homeopathy and only $7.7 \%$ of them used prophylactic medications.

Table 2.13: MIDAS

\begin{tabular}{|c|c|}
\hline MIDAS degree & \\
\hline I & $477(68.4 \%)$ \\
\hline$\Pi$ & $99(14.2 \%)$ \\
\hline Ш & $86(12.3 \%)$ \\
\hline IV & $34(4.8 \%)$ \\
\hline
\end{tabular}

Participants in our study reported of headache related disability, that is $68.4 \%$ had MIDAS score of grade I, $14.2 \%$ had grade II, $12.3 \%$ had grade III, and $4.8 \%$ had grade IV.

\section{Volume 6 Issue 7, July 2017 www.ijsr.net}




\section{International Journal of Science and Research (IJSR)}

ISSN (Online): 2319-7064

Index Copernicus Value (2015): 78.96 | Impact Factor (2015): 6.391

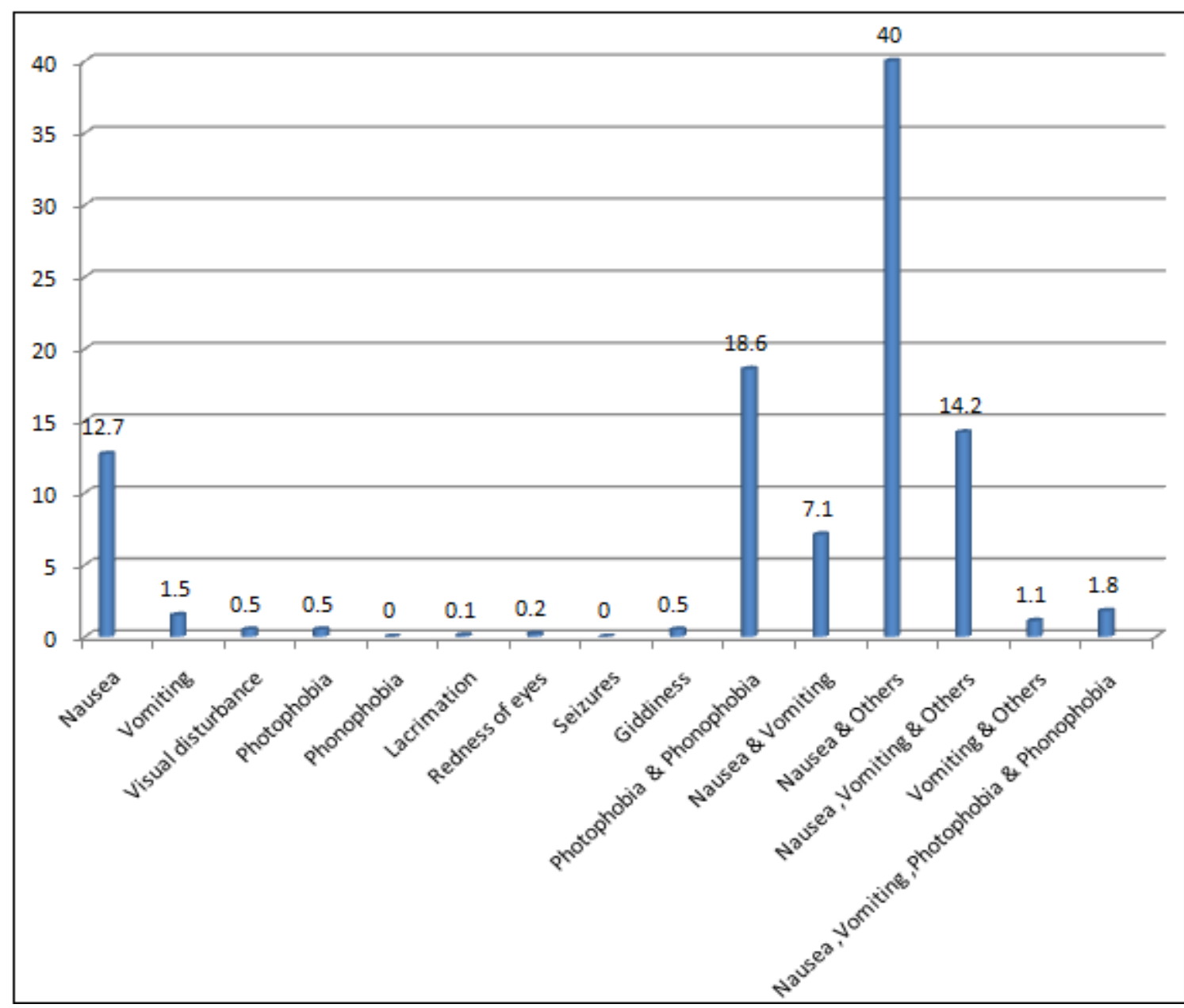

Figure 1: Associated factors of migraine

Among the associated symptoms, nausea with other factors (40\%) was the commonest associated symptom, followed by photophobia with phonophobia (18.6\%) and other factors like nausea $(12.7 \%)$, vomiting $(1.5 \%)$, visual disturbance $(0.5 \%)$, Lacrimation $(0.1 \%)$, Giddiness $(0.5 \%)$, Redness of eyes $(0.2 \%)$ and $1.8 \%$ had nausea, vomiting, photophobia and phonophobia.

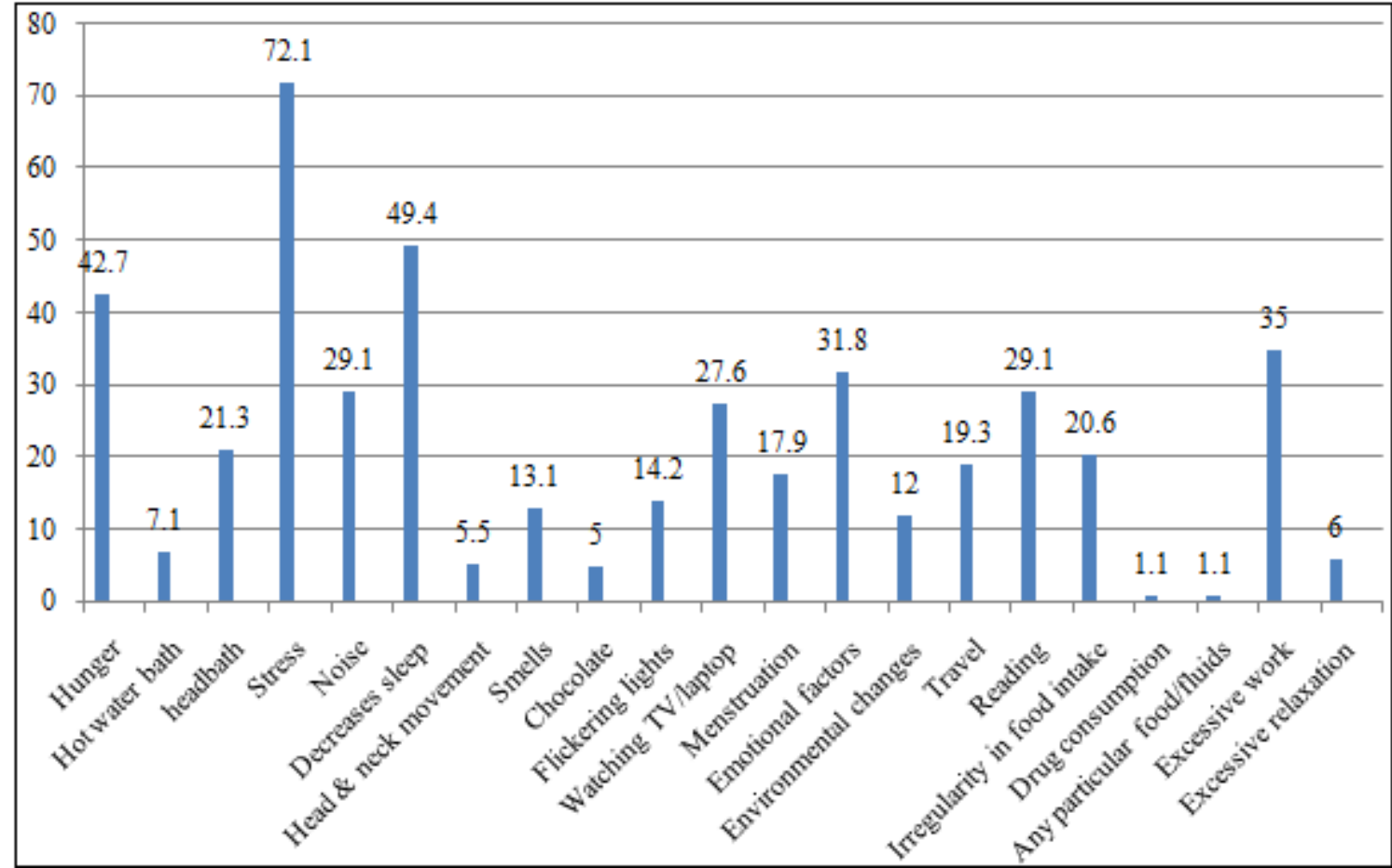

Figure 2: Attacks Triggered by exposure to various factors

Volume 6 Issue 7, July 2017 www.ijsr.net

Licensed Under Creative Commons Attribution CC BY 


\section{International Journal of Science and Research (IJSR) \\ ISSN (Online): 2319-7064 \\ Index Copernicus Value (2015): 78.96 | Impact Factor (2015): 6.391}

Among the triggering factors, hunger, hot water bath, head bath, stress, noise, decreased sleep, odour, chocolate consumption, flickering lights, watching TV/laptops, menstruation, emotional factors, weather changes, travel, reading, irregularity in food intake, excessive work were statistically significant. $(\mathrm{P}=<0.0001$ Figure: 1$)$.

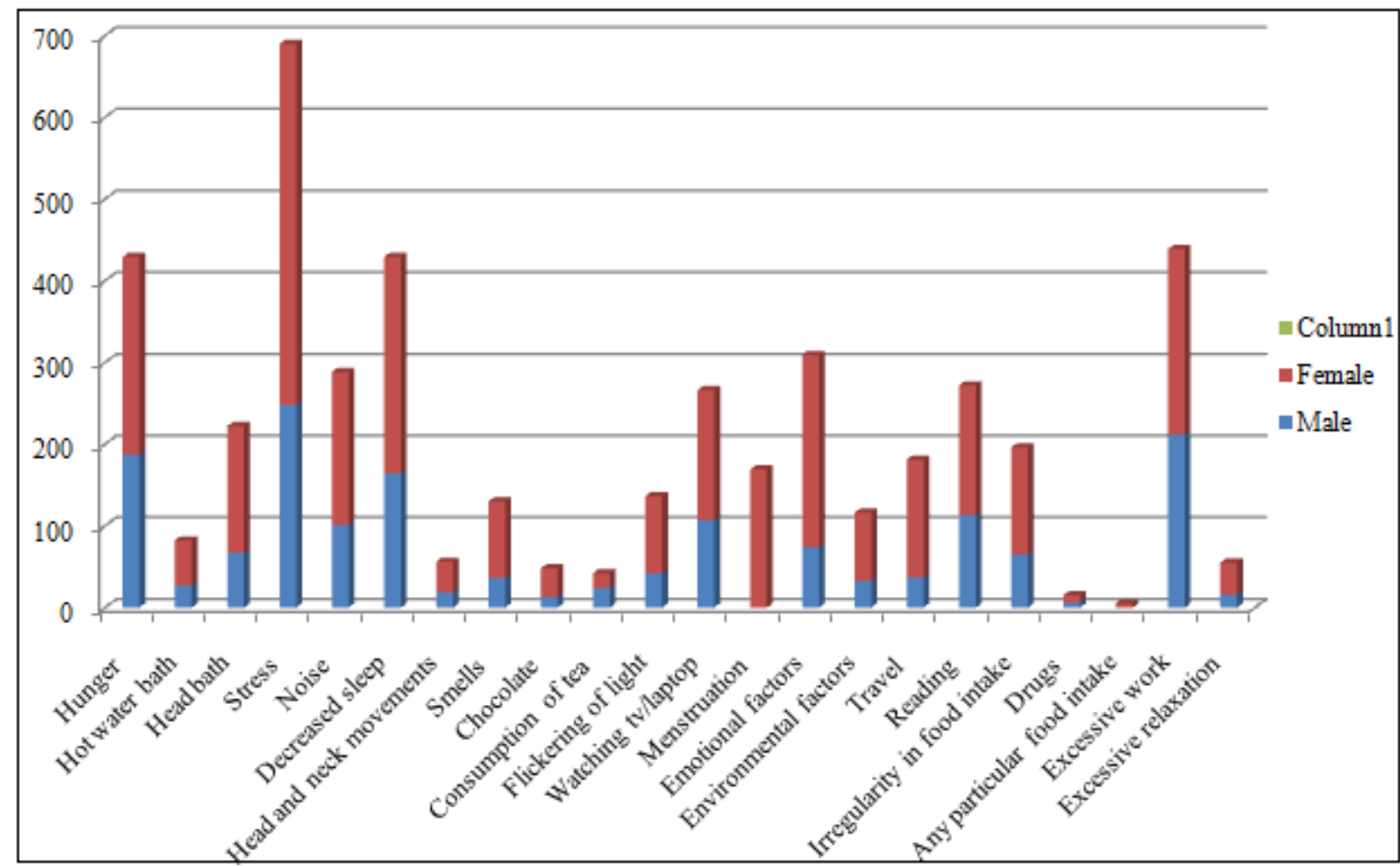

Figure 3: Gender and trigger factors

Our study found predominance of females with migraine.

Also stress, decreased sleep and hunger were the commonly

reported triggering factors in females.

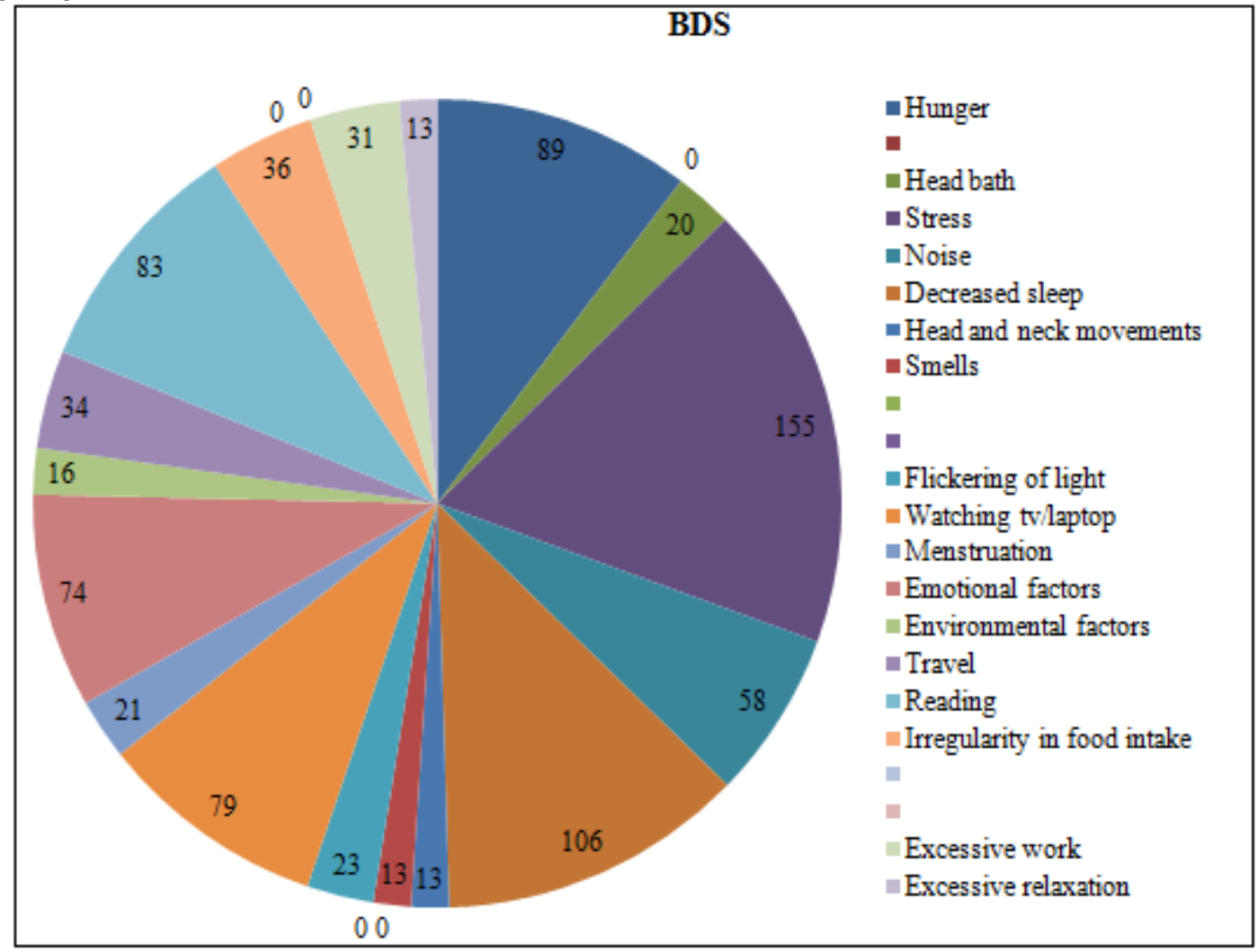

Figure 4.1: Frequency of triggering factors among different courses

Volume 6 Issue 7, July 2017 www.ijsr.net

Licensed Under Creative Commons Attribution CC BY 


\section{International Journal of Science and Research (IJSR) \\ ISSN (Online): 2319-7064 \\ Index Copernicus Value (2015): 78.96 | Impact Factor (2015): 6.391}

Among dental students, stress, decreased sleep and hunger migraine.

were the commonest triggering factors reported with

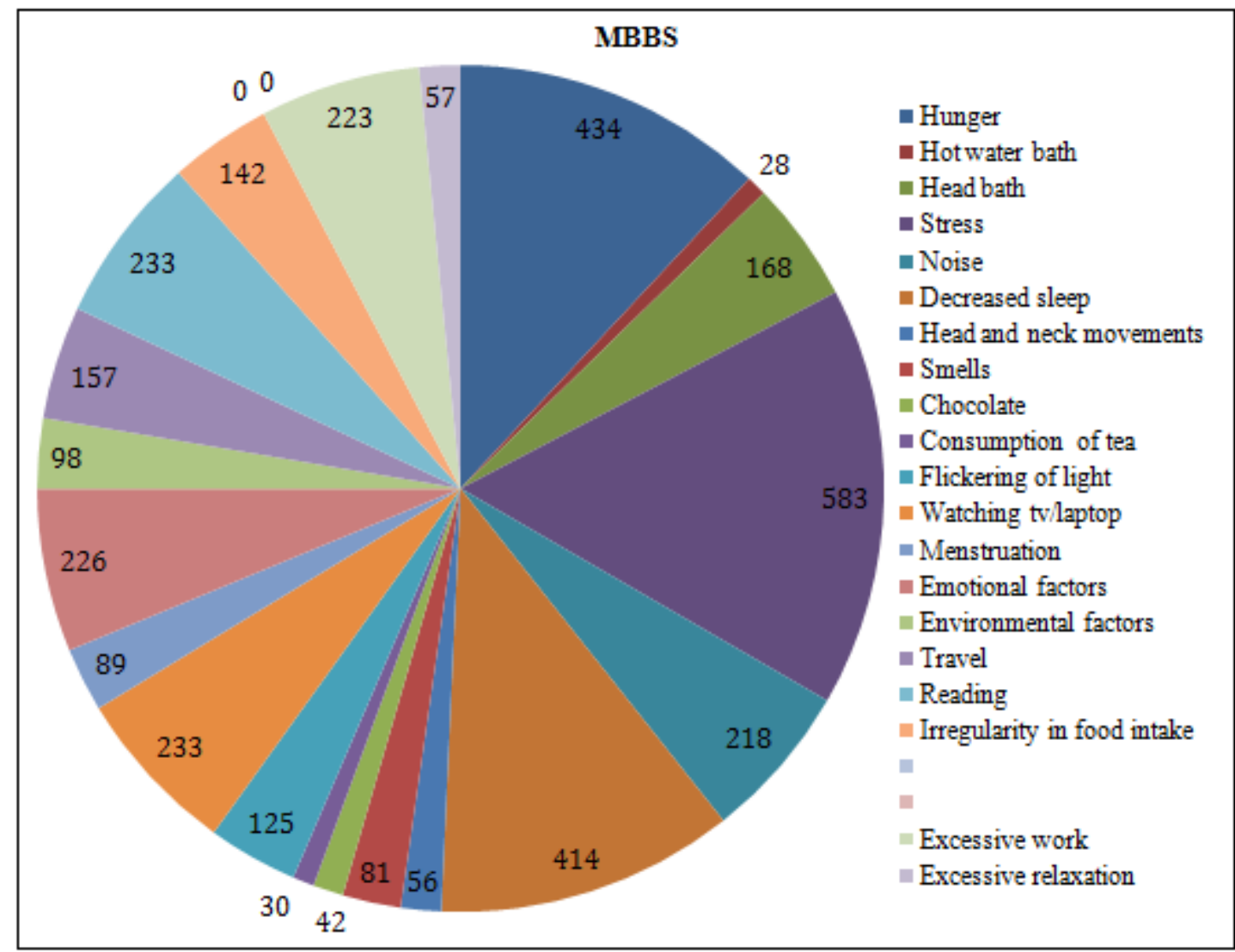

Figure 4.2: MBBS

Among medical students too stress, hunger and decreased sleep were the commonly reported triggering factors.

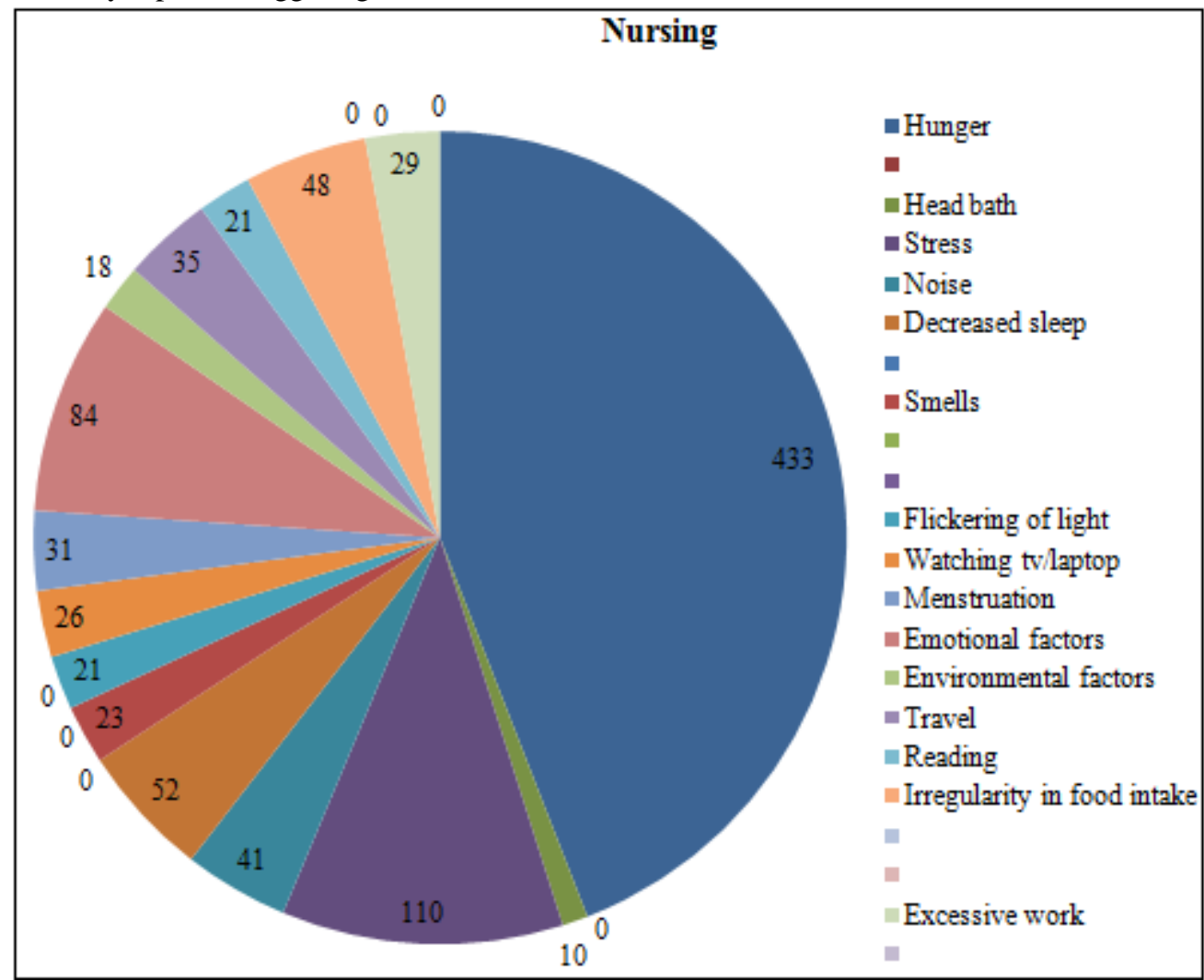

Figure 4.3: Nursing

Volume 6 Issue 7, July 2017

www.ijsr.net

Licensed Under Creative Commons Attribution CC BY 


\section{International Journal of Science and Research (IJSR) \\ ISSN (Online): 2319-7064}

Index Copernicus Value (2015): 78.96 | Impact Factor (2015): 6.391

However nursing students reported hunger as the emotional factors. commonest triggering factor followed by stress and

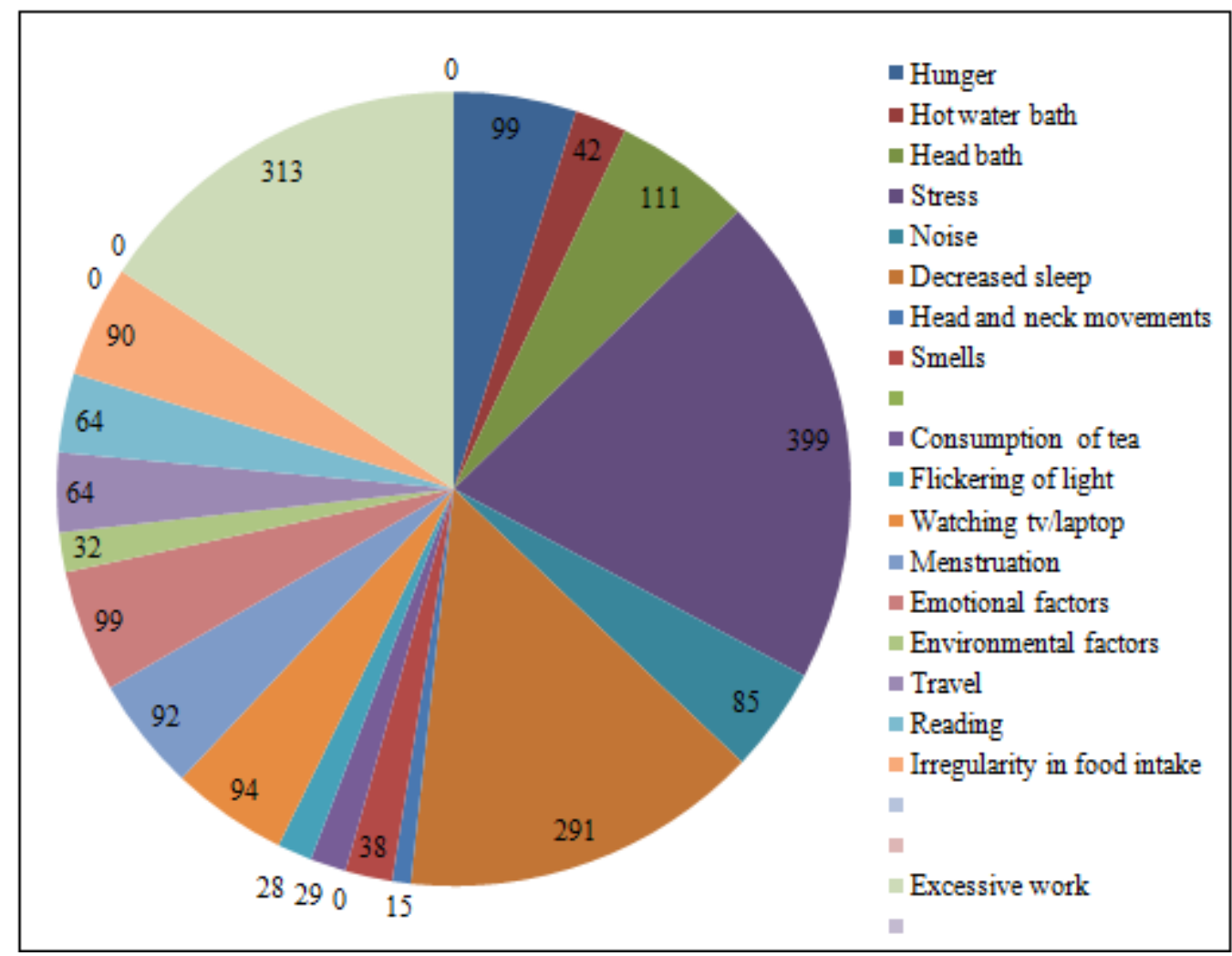

Figure 4.4: Postgraduate(PG) \& Staff

Post graduates and staff also reported stress as the commonest triggering factor followed by environmental changes and decreased sleep.

\section{Discussion}

Migraine is a highly prevalent and disabling subtype of primary headache and a benign neurological disorder. The present study was aimed at identifying the triggering factors and their frequency, emphasising the importance of awareness and avoidance of trigger factors. The study consisted of 2050 participants, cross-sectional assessment was done both by structured and unstructured clinical interview using a specially designed proforma to collect socio-demographic details, Visual Analogue Scale(VAS) for pain and Migraine Disability Assessment Questionnaire (MIDAS). Out of 2050 participants 697 of them had migraine type headache.

The study subjects were recruited on a purposive basis and their socio demographic background showed that majority were females (461) out of 697 migraineurs. The mean age of the subjects recruited here has been $23.5 \pm 6.0$ (Table 1.1). At present, studies on the negative impact of migraine among adults are limited primarily to population-based samples of adults aged $30-65^{[24],[16]}$. In our sample, $552(79.7 \%)$ of the study subjects belonged to $18-25$ years of age constituting the majority. Our study showed high prevalence of migraine in females 461(62.1\%) compared to that of males
236(33.8\%), as already demonstrated in previous studies conducted by Bindu Menon et ${ }^{\text {al[17] }}$, Galinovic et al ${ }^{[18]}$ and Sanvico et al ${ }^{[19]}$. However this finding should be interpreted with caution as our sample had more female participants. The higher frequency of migraine was found in MBBS students $357(51.4 \%$ ) followed by Postgraduates and Staff $158(22.6 \%), 108(15.4 \%)$ in BDS and $74(10.6 \%)$ in Nursing students respectively.

In our study, prevalence of migraine was found to be $697(34 \%)$, out of which 541(77.6\%) were not associated with aura and 156(22.3\%) were associated with aura, similar to studies conducted by Marianges Zandrozny et al ${ }^{[20]}$ and a study conducted by IHS .However studies have shown variation in migraine prevalence because of number of methodological challenges as previously reported by Leonardi et al ${ }^{1}$.

The most characteristic headache was pulsating 360(51.6\%), followed by more than one type $153(21.9 \%)$ and throbbing type $129(18.5 \%)$ respectively. These findings are similar to a previous study conducted by Lipton et al ${ }^{[23]}$. 88.6\% had 510 attacks per month, followed by $8.3 \%$ had $10-15$ attacks and $3 \%$ had more than 15 attacks per month. $86.5 \%$ of them had duration of each attack of 4-12 hours.64.9\% had gradual onset and $35 \%$ had sudden onset of migraine headache, $83.2 \%$ had intermittent headache whereas $16.7 \%$ had continuous headache. In our study $31.4 \%$ had unilateral headache and $22 \%$ had more than one site of headache, this 


\section{International Journal of Science and Research (IJSR) \\ ISSN (Online): 2319-7064}

Index Copernicus Value (2015): 78.96 | Impact Factor (2015): 6.391

was similar to previous studies done. Family history of migraine was seen in $23.8 \%$, this finding is similar to other studies which show high positive family history, Smitherman et al ${ }^{[26]}$, Bindu et al ${ }^{[17]}$, Ojini et al ${ }^{[21]}$, Panda et

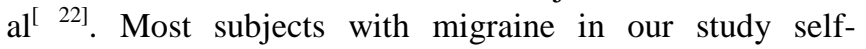
medicated with non-prescription over the counter drugs( $80.2 \%)^{[17],[30],[35],[41],[42], 59]}, 67.5 \%$ used NSAID's followed by prophylactic medication (7.7\%), 2\% used opioids ,triptans and $0.4 \%$ used homeopathy. Surprisingly only few used prophylactic medication and triptans. Subjects also reported several non-drug strategies to relieve of migraine headache like sleep $(71.1 \%)$, followed by rest $(58.3 \%)$, massage $(26.9 \%)$, entertainment $(9.4 \%)$, vomiting $(6.3 \%)$, change of posture $(2.5 \%)$ and head massage $(2.1 \%)$, which was also reported by Bindu et $\mathrm{al}^{17}$ and by Marianges Zandrozny et al [20] Also some of them reported relief after masturbation $(0.1 \%)$, intake of food $(0.1)$ and consumption of coffee $(0.2 \%) .77 .1 \%$ had moderate intensity of pain on visual analogue scale, $13.6 \%$ reported mild intensity of pain and $9.1 \%$ had sever intensity of pain, similar to Bindu et al ${ }^{[17]}$ Ojini et $\mathrm{al}^{[21]}$.

Participants in our study reported headache related disability that is $68.4 \%$ reported MIDAS score of grade I, $14.2 \%$ had grade II, $12.3 \%$ had grade III, and $4.8 \%$ had grade IV Linde et $\mathrm{al}^{[2]}$, Smitherman et al ${ }^{[26]} \mathrm{Bi}$, ndu et al ${ }^{[17]}$, Aoao Eliezer Serri-de-barros et al ${ }^{[24]}$. Absenteeism from work/college was seen in $21 \%$ of the participants with days ranging from 1-2 days, while $32 \%$ had decreased productivity at work/college, $50 \%$ had to miss household work, social and leisure activities in the last three months for about 1-2 days.

Our study showed nausea with other factors (40\%) was the commonest associated symptom, followed by photophobia with phonophobia $(18.6 \%)$ and other factors like nausea $(12.7 \%)$, vomiting $(1.5 \%)$,visual disturbance $(0.5 \%)$ lacrimation $(0.1 \%)$, giddiness $(0.5 \%)$, redness of eyes $(0.2 \%)$ and $1.8 \%$ had nausea vomiting photophobia and phonophobia. These findings are consistent with other studies, Bindu et al ${ }^{[17]}$, Dokhari et al ${ }^{[25]}$.

The results showed that most patients exhibited multiple triggering factors. Stress was the commonest triggering factor $(72.1 \%)$ which is consistent with other studies [17][26][27][28][29][30][31][32]. Others included mainly decreased sleep $(49.4 \%)$, hunger $(42.7 \%)$, excessive work $(35 \%)$, emotional factors $(31.8 \%)$, noise $(29.1 \%)$ and reading (29.1\%). Most participants also reported susceptibility to environmental and hormonal triggers like, head bath $(21.3 \%)$, irregularity in food intake $(20.6 \%)$, hot water bath (7.1\%), watching TV/laptop (27.6\%), flickering lights $(14.2 \%)$, weather changes (12\%), travel $(19.3 \%)$, odour $(13.1 \%)$ excessive relaxation $(6 \%)$, head and neck movement $(5.5 \%)$ and menstruation $(17.9 \%)$. Earlier studies have also reported similar findings [17],[26],[28],[33],[34],[35],[36] ,[37],[38].

Only few participants reported susceptibility to dietary factors like chocolate $(5 \%)$, Chinese food $(0.1 \%)$, spicy food
$(0.1 \%)$, sweets $(0.1 \%)$, consumption tea/alcohol/coffee $(1.1 \%)$ and fruits like grapes and pineapple $(0.1 \%)$, these finding are consistent with other studies ${ }^{[26][30],[39],[40][41]}$.

Stress, in turn was the most prevalent trigger in the present study among either gender or different courses.

\section{Conclusion}

This study concluded that subjects in a medical college setup with migraine exhibited multiple triggering factors. Stress was the commonest triggering factor and also showed headache related disability like absenteeism and decreased productivity of work. Also self-medication and nonpharmacological strategies were commonly practised.

\section{References}

[1] Leonardi M. The global burden of migraine: Measuring disability in headache disorders with WHO's Classification of Functioning, Disability and Health (ICF) J Headache Pain. 2005;6:429-40.[PMC free article] [PubMed]

[2] Linde M. Attitudes and burden of disease among selfconsidered migraineurs: A nation-wide populationbased survey in Sweden. Cephalalgia. 2004;24:45565. [PubMed]

[3] Mitsikostas DD, Gatzonis S, Thomas A, Kalfakis N, Ilias A, Papageoergiou C. An epidemiological study of headaches among medical students in Athens. Headache 1996; 36:561-4.

[4] Stovner L, Hagen K, Jensen R, et al. The global burden of headache:A documentation of headache prevalence and disability worldwide. Cephalalgia. 2007;27:193210.

[5] WHO link - fact sheets oct 2012 headache disorders WHO .

[6] Amico D D ,Grazzi L.,Bussone G .,Topiramate in the prevention of migraine: a review of its efficacy, tolerability and acceptability, Neuropsychiatric Disease and Treatment, 2006, 2(3), 261-267.

[7] Types of migraine. Available at: http://www.achenet.org/resources/migraine_without_au ra. Accesed on 5/10/2014

[8] Minton G C., Miller A D., Bookstaver PB and Love B L, Topiramate Safety and Efficacy of its Use in the Prevention and Treatment of Migraine. Journal of Central Nervous System Disease, 2011, 3 , 155- 168.

[9] YiyiGuo, Ximei Han., Tingmin Yu., Gang YaoMetaanalysis of efficacy of topiramate in migraine prophylaxis. Neural Regen Res, 2012,7(23), 1806-1811.

[10] Bradley WG., Daroff RB., Fenichel GM., Jankovic J ,Neurology in clinical practice 6thedn,Philadelphia,2012.

[11] Martin PR. Behavioral management of migraine headache triggers: learning to cope with triggers. Curr Pain Headache Rep. 2010;14:221-227.

[12] Fukui PT, Gonçalves TRT, Strabelli CG, et al. Trigger factors in migraine patients. ArqNeuropsiquiatr. 2008;66:494-499.

[13] Millichap JG, Yee MM. The diet factor in pediatric and adolescent migraine. Pediatr Neurol. 2003;28:9-15.

\section{Volume 6 Issue 7, July 2017}




\section{International Journal of Science and Research (IJSR) \\ ISSN (Online): 2319-7064 \\ Index Copernicus Value (2015): 78.96 | Impact Factor (2015): 6.391}

[14] Breslau N, Rasmussen BK. The impact of migraine: epidemiology, risk factors, and co-morbidities. Neurology. 2001;56(Suppl 1):S4-S12.

[15] Dyrbye LN,Thomas MR, Shanafelt TD. Systematic review of depression, anxiety, and other indicators of psychological distress among U.S. and Canadian medical students. Acad Med. 2006;81: 35473. [PubMed]

[16]Bindu Menon and Neeharika Kinnera Prevalence and characteristics of migraine in medical students and its impact on their daily activities. Annals of Indian academy of neurology, volume 16,issue 2,page -221 to 225.

[17] Galinović $\mathrm{I}^{1}$, Vuković V, Troselj M, Antić S, Demarin V. Migraine and tension-type headache in medical students: CollAntropol. 2009 Mar;33(1):169a questionnaire study.

[18] Sanvito WL, Monzillo PH, Peres MF, Martinelli MO, Fera MP, Gouveia DA, et al. The epidemiology of migraine in medical students. Headache. 1996;36:3169. [PubMed]

[19] Marianges Zandrozny Gouvêa da Costa, MD; Cláudia BernadetSoares, MD; Liana Miriam Miranda Heinisch, MSc; Roberto Henrique Heinisch, MSc Frequency of Headache in the Medical Students ofSanta Catarina's Federal University Headache 2000;40:740-744)

[20] Ojini FI, Okubadejo NU, Danesi MA. Prevalence and clinical characteristics of headache in medical students of the University of Lagos, Nigeria. Cephalalgia. 2009;29:472-7. [PubMed].

[21] Panda $S^{1}$, Tripathi M. Clinical profile of migraineurs in a referral centre in India. $J$ Assoc Physicians India. 2005 Feb;53:111-5.

[22] Bokhari FA, Sami W, Shakoori TA, Ali SA, Qureshi GA. Clinical characteristics of 226 college-going female migraineurs in Lahore, Pakistan - putting ICHD-2 to the road test. NeuroEndocrinolLett.2008;29:96570. [PubMed]

[23] João Eliezer Ferri-de-Barros1, Mauricio José de Alencar2, Luis Felipe Berchielli3, Luis Carlos Castelhano Junior3 Headache among medical and psychology students Arq Neuropsiquiatr 2011;69(3):502-508 502.

[24]F. Camboim Rockett, K. Castro1, V. Rossoni de Oliveira, A. da SilveiraPerla, M. L. Fagundes Chaves and I. D. Schweigert Perry1,4 Perceived migraine triggers; do dietary factors play a role? Nutr Hosp. 2012;27(2):483-489.

[25] Jasem Y Al-Hashel1,2, Samar Farouk Ahmed1,3*, Raed Alroughani4,5 and Peter J Goadsby6Migraine among medical students inKuwait University The Journal of Headache and Pain 2014, 15:26

[26] AW Hauge, M Kirchmann and J Olesen Trigger factors in migraine with aura Cephalalgia 30(3) 346-353.

[27] Gholamreza Sharifirad, Abdoljalal Marjani, Charkazi Abdolrahman, Qorbani Mostafa, and ShahnaziHossein Stress among Isfahan medical sciences students J Res Med Sci. 2012 Apr; 17(4): 402-406. PMCID: PMC3526138.

[28]Ehsan K. Al-Shimmery Precipitating and Relieving Factors of Migraine Headache in 200 Iraqi Kurdish Patients Oman Medical Journal 2010, Volume 25, Issue 3, July 2010.
[29] Yadav RK ${ }^{1}$, Kalita J, Misra UK. A study of triggers of migraine in India. Pain Med. 2010 Jan;11(1):44-7. doi: 10.1111/j.1526-4637.2009.00725.x. Epub 2009 Sep 29.

[30] Yalinay Dikmen $\mathrm{P}^{1}$, Yavuz BG, Aydinlar EI. The relationships between migraine, depression, anxiety, stress, and sleep disturbances. ActaNeurol Belg. 2014 Jun 3.

[31]K Ravishankar 'Hair wash' or 'head bath' triggering migraine - observations in 94 Indian patients Cephalalgia, 2006, 26, 1330-1334.

[32] W Mak , KL Tsang, TH Tsoi, KM Au Yeung3, KH Chan, TS Cheng, TFR Cheung \& SL Ho Bath-related headache Cephalalgia, 2004, 25, 191-198.

[33] Andressa Marmore de Lima1, Giovanna Baptista Sapienza1, Vinícius de Oliveira Giraud1, YáraDadalti Fragoso2 Odors as triggering and worsening factors for migraine in men ArqNeuropsiquiatr 2011;69(2-B):324327324

[34] Hirsch AR. Olfaction in migraineurs. Headache. 1992 May;32(5):233-6.

[35] Vincent $\mathrm{MB}^{1}$. Headache and neck. Curr Pain Headache Rep. 2011 Aug;15(4):324-31. doi: 10.1007/s11916-0110195-1.

[36] Dan Levy, PhD; Andrew M. Strassman ; Rami Burstein A Critical View on the Role of Migraine Triggers in the Genesisof Migraine Pain . 954 | Headache | June 2009.

[37] Fernanda C Rockett, Vanessa R de Oliveira, Kamila Castro, Márcia LF Chaves, Alexandre da S Perla, and Ingrid DS PerryDietary aspects of migraine trigger factors Nutrition Reviews ${ }^{\circledR}$ Vol. 70(6):337-356

[38] Panconesi A, Bartolozzi ML, Mugnai S, Guidi L. Alcohol as a dietary trigger of primary headaches: what triggering site could be compatible? 2012 May;33 Suppl 1:S203-5. doi: 10.1007/s10072-012-1068-z.

[39] Panconesi $A^{1}$, Bartolozzi ML, Guidi L. Curr Pain Headache Rep. Alcohol and migraine: what should we tell patients? 2011 Jun;15(3):177-84. doi: 10.1007/s11916-011-0184-4. 